\title{
Profissionais do acolhimento institucional: a atuação perante a chegada de uma criança
}

\author{
Monalisa Pereira Furtado* \\ Agnes de Maria Júnior da Silva** \\ Juliana Oliveira dos Santos*** \\ Celina Maria Colino Magalhães****
}

\begin{abstract}
Resumo
O presente trabalho foi realizado no contexto do acolhimento institucional. Teve por objetivo examinar de que forma os profissionais atuam na chegada de uma criança. Para isso tomou-se os relatos de 16 educadores e sete membros da equipe técnica, por meio de questionários para a caracterização sociodemográfica e entrevista semiestruturada. $\mathrm{O}$ resultado das entrevistas foi analisado pelo software IRaMuTeQ ${ }^{\circledR}$. Os principais resultados foram: 1) Maioria dos profissionais eram do sexo feminino, concursados, com ensino superior e capacitação recente; 2) No momento da chegada das crianças à instituição os profissionais agem de forma a explicar os motivos do acolhimento; 3) É comum a emissão de comportamentos de rotina; 4) Existe pouco contato dos educadores com as famílias; 5) As crianças possuem dificuldade para se adaptar à rotina da instituição. Conclui-se que a equipe atua tentando suprir as necessidades físicas e emocionais das crianças, mas estas continuam manifestando dificuldades em se adaptar.

Palavras-chave: Acolhimento institucional; Educador social; Equipe multiprofissional.
\end{abstract}

\section{Institutional shelter workers: their action upon the Childs admission}

\begin{abstract}
The current study was performed at an institutional shelter. The aim was to assess how the workers act upon the admittance of a child. To do that we took the statements of 16 educators and seven members of the technical staff through a questionnaire for social demographic characterization and semi-structured interview. The results of the interview were analyzed with the use of IRaMuTeQ ${ }^{\circledR}$ software. The main results were: 1) most workers were women, admitted through public contest, had college education and recent training; 2) upon the admittance of the children in the institution the workers attitude is to explain to the children the reason for their sheltering; 3 ) it is common the emission of routine behavior; 4) there is little contact between the educators and the children's families; 5) the children have difficulties to adapt to the institution routine. It is concluded that the team work is designed to suppress the children's physical and emotional needs, however they still demonstrate difficulties in adapting themselves. Keywords: Institutional sheltering; Social educator; Multi professional team.
\end{abstract}

* Graduanda em Psicologia UFPA e Bolsista IC (CNPq)

** Mestranda do Programa de Pós-Graduação em Teoria e Pesquisa do Comportamento da UFPA.

*** Graduanda em Psicologia UFPA e Bolsista IC (CNPq)

****Doutora em Psicologia Experimental pela USPSP, Diretora do Núcleo de Teoria e Pesquisa do Comportamento e Professora titular da UFPA. 


\section{Introdução}

No ano de 1990, foi promulgado o Estatuto da Criança e do Adolescente (ECA), que carrega consigo a mudança no paradigma da assistência existente até então, a partir dele a criança e o adolescente tornam-se sujeitos de direitos e prioridade absoluta, em condição peculiar do desenvolvimento, e que, por essa razão necessitam de proteção integral (Cruz, 2014). Com a divulgação do ECA (1990), passa-se a dar destaque ao direito da criança e do adolescente a permanecerem em convivência familiar. O artigo 101 rege que o acolhimento institucional se caracteriza enquanto a sétima medida aplicável em situações nas quais ocorre violação de quaisquer dos direitos da criança e do adolescente. Ou seja, ela deve ser tomada quando esgotadas as tentativas de manutenção da criança no convívio familiar. É uma medida utilizada como transição à reintegração familiar e, na impossibilidade desta, a colocação em família substituta.

O ECA (1990) rompe com práticas de internação e exclusão, outrora assegurados por lei e estipula que o tempo de permanência máxima de uma criança ou adolescente em instituição de acolhimento não deve exceder dois anos. Atualmente o período máximo de permanência foi reduzido para 18 meses, conforme o Artigo 162 da Lei 13.509 (2017). Com esse objetivo, logo após o acolhimento da criança cabe à equipe técnica da instituição elaborar um Plano de Atendimento Individual (PIA), desenvolvido na entrada da criança e construído processualmente, reavaliado a cada três meses, nele devem constar os objetivos, estratégias e ações pensadas pelo serviço de acolhimento que visem a superação dos motivos que levaram ao acolhimento.

Com o intuito de nortear os serviços de acolhimento surge o documento Orientações Técnicas para Serviços de Acolhimento para Crianças e Adolescentes (2009), ele delimita desde as condições materiais até os recursos humanos indispensáveis ao funcionamento das instituições. Dentre os princípios presentes no documento estão: a excepcionalidade e provisoriedade do afastamento do convívio familiar, preservação e fortalecimento dos vínculos familiares e comunitários, garantia de acesso à rede de assistência (política de saúde, de educação, esporte e cultura), oferta de atendimento personalizado e individualizado.

Os efeitos da inexistência ou fragilidade dos vínculos familiares outrora existentes podem ser agravados por conta da permanência prolongada em ambiente institucional, devido a carência de adultos cuidadores dispostos a estabelecer e manter uma ligação estável e duradora, do atendimento em massa e padronizado, que costuma caracterizar as instituições de acolhimento. Dessa forma, essa vivência sobre a formação da identidade e o sentimento de segurança emocional podem resultar em uma criança ainda mais vulnerável a doenças físicas e psíquicas, além de acarretar dificuldades de relacionamento em grupos, convívio social, entre outros danos (Cavalcante, Silva e Magalhães, 2010).

A vinculação afetiva se caracteriza enquanto a tentativa de manutenção da proximidade entre os pares vinculados. Como consequência, qualquer tentativa de separar um par vinculado resulta em resistência por parte de ambos. Dessa forma, o afastamento acarreta ansiedade e a perda definitiva gera tristeza e ambas despertam sentimento de raiva no indivíduo (Bowlby, 1979/2001). Assim sendo, é essencial a manutenção e fortalecimento do vínculo familiar, para isso o diálogo com os técnicos se faz fundamental, na medida em que é necessário que o sujeito inserido na instituição tenha a consciência de que não se encontra ali por ter sido abandonado por sua família, mas que existe um contexto maior do qual ele faz parte. Tais informações devem ser repassadas ao indivíduo quantas vezes forem necessárias a fim de propiciar o seu entendimento durante todo o processo de acolhimento.

As Orientações Técnicas (2009) salientam a importância de se manter uma vinculação da equipe técnica em relação aos infantes, sendo fundamental o diálogo entre ambos, em vista de garantir o amparo da criança acolhida, tanto em relação às suas necessidades básicas, quanto para lhe garantir o direito de conhecer e compreender os motivos de sua permanência na mesma. A rede social formada por profissionais e funcionários das instituições de acolhimentos possui a função de dar apoio, orientação e informação às crianças, pois no momento de separação da criança do convívio familiar as funções de afeto e cuidado são transferidas para os cuidadores e técnicos das instituições de acolhimento (Penso \& Moraes, 2016).

Faz-se importante conhecer quem são os profissionais que atuam em uma instituição de acolhimento e de que forma eles lidam com o seu trabalho no dia-a-dia, pois são capacidades indispensáveis ao profissional que atua em instituição de acolhimento a atenção para as trocas afetivas e uma boa competência emocional no trato com a criança, devido os rompimentos de laços possivelmente ocorridos, como com a família de origem e comunidade (Mendes \& Kappler, 2018). Além do mais, é necessário perceber como eles concebem a figura das 
crianças pelas quais são responsáveis e de seus familiares (Cavalcante \& Corrêa, 2012; Cintra \& Souza, 2010; Rossetti-Ferreira, Almeida, Costa, Guimarães, Mariano, Teixeira, 2012).

As pesquisadoras Cavalcante e Corrêa (2012) apontam que um dos momentos em que as crianças acolhidas possuem maior dificuldade é na chegada à instituição, uma vez que ela irá se deparar com um ambiente novo, com regras e rotinas anteriormente desconhecidas. Dessa forma o presente estudo teve como objetivo examinar de que forma os profissionais direcionam a sua atuação nesse momento em especial. Ou seja, como eles recebem a criança na sua chegada à instituição, como eles irão dialogar a respeito dos motivos que a levaram até o espaço, suas ações e práticas cotidianas direcionadas a auxiliar nessa fase inicial de adaptação.

\section{Método}

\section{Participantes}

Fizeram parte do estudo 16 educadores e sete membros da equipe técnica, dentre elas três assistentes sociais, uma terapeuta ocupacional, uma psicóloga, uma pedagoga e a coordenadora da instituição. Os dados foram coletados no período de outubro de 2017 a julho de 2018. Os critérios para inclusão dos participantes foram: educadores e técnicos que possuíssem o tempo mínimo de seis meses na instituição e que assinassem o Termo de Consentimento Livre e Esclarecido.

\section{Ambiente}

Os dados foram coletados em uma instituição de acolhimento infantil da Região Metropolitana de Belém, mantida pela prefeitura e destinada a crianças na faixa etária de zero a seis anos de ambos os sexos. O espaço tem capacidade para acolher até 20 crianças e conta com uma equipe formada por psicólogo, pedagogo, assistente social e educadores.

\section{Instrumentos}

Foi utilizado questionário de caracterização dos profissionais, que visa mapear o perfil sociodemográfico, dados da satisfação profissional, concepções e práticas de cuidado dos profissionais. O questionário foi utilizado nos estudos de Cavalcante (2008) e Corrêa (2016). O conteúdo do instrumento foi adaptado a partir dos objetivos da presente pesquisa e utilizou-se itens dos tópicos dados pessoais e dados profissionais.

\section{Procedimentos}

\section{1-Autorização para realização do estudo nas instituições}

Foi contatada a rede de acolhimento do Estado, setor de coordenadoria de proteção social especial de alta complexidade, para apresentação da pesquisa e solicitação de permissão para ingresso nas dependências das instituições, para ter acesso aos prontuários e à equipe de educadores responsáveis pelo cuidado dos participantes. A submissão do projeto ao Comitê de Ética em pesquisa (Protocolo $n^{\circ}$ 568.256) foi feita concomitante à solicitação de autorização institucional.

\section{2-Reconhecimento do ambiente institucional}

Foi realizado evento com a diretoria e equipe técnica da instituição para apresentar a pesquisa a ser desenvolvida no espaço, em vista de motivar a receptividade da equipe técnica e agendar os dias de visitas à instituição.

Para além disso, realizou-se também a inserção ecológica, ela propõe que o pesquisador esteja inserido no contexto ecológico ao qual o participante da pesquisa se encontra, para que, dessa forma ele possa conhecer a realidade desse sujeito. Assim é possível que o pesquisador faça parte do ambiente ecológico e vivencie o espaço e as relações presentes nele (Rosa, Nascimento, Santos, Melo \& Souza, 2016). Para esse fim foi realizado o acompanhamento da dinâmica da instituição por meio de visitas regulares, observações e participação nas atividades cotidianas.

\section{3-Coleta de dados}

As fichas de caracterização dos educadores e dos técnicos foram preenchidas pela pesquisadora nas dependências da instituição e os dados coletados por meio de entrevista. Logo após o preenchimento da caracterização foi realizada a pergunta disparadora. Fez-se uso de gravador para registro das respostas e posterior transcrição. A entrevista foi realizada em local reservado e individualmente.

\section{Análise de dados}

Os dados sociodemográficos das crianças e dos profissionais foram sistematizados a partir do Excel para elaboração das tabelas. As entrevistas realizadas com os profissionais foram armazenadas em áudio, e posteriormente transcritas em formato de texto eletrônico para que seus dados pudessem ser processados pelo software 
IRaMuTeQ (Interface de $\mathrm{R}$ pour les Analyses Multidimensionnelles de Textes et de Questionnaires), que faz a análise lexical automática das palavras presentes nos discursos dos entrevistados. A versão utilizada foi a 0.7 alpha 2 , disponível no site responsável pela divulgação do software (http://www.iramuteq.org/). Todos os dados coletados foram discutidos por meio da literatura.

\section{Resultados e discussão}

A análise do Perfil sociodemográfico dos educadores e técnicos demonstram que a maioria dos funcionários da instituição é do sexo feminino (86\%) e se encontram em uma faixa etária acima de 36 anos (82\%).

Tabela 1. Perfil sociodemográfico dos educadores e técnicos

\begin{tabular}{l|r|r}
\hline & $\mathrm{N}=22$ & $\%$ \\
\hline Sexo & & \\
\hline Feminino & 19 & 86 \\
\hline Masculino & 3 & 14 \\
\hline Faixa etária & 4 & 18 \\
\hline De 22 a 36 anos & 18 & 82 \\
\hline Acima de 36 & & \\
\hline Escolaridade & 9 & 40 \\
\hline Ensino médio & 13 & 60 \\
\hline Ensino superior & & \\
\hline Graduação & 4 & 18 \\
\hline Serviço Social & 1 & 4 \\
\hline Terapia Ocupacional & 1 & 4 \\
\hline Administração & 1 & 4 \\
\hline Psicologia & 7 & 30 \\
\hline Pedagogia & 9 & 40 \\
\hline Não possui & & \\
\hline Capacitação & 16 & 72 \\
\hline Sim & 6 & 28 \\
\hline Não & & \\
\hline Situação & 16 & 72 \\
\hline Concursado & 6 & 28 \\
\hline Contratado & &
\end{tabular}

Os documentos oficiais são lacunosos em relação a delimitar um gênero para a atuação de educadores em instituições de acolhimento. No entanto, o estudo de Bueno, Magalhães e Vieira (2018)aponta que, assim como na educação infantil, as mulheres são maioria na dedicação à educação de crianças, por serem vistas como figuras de cuidado e zelo. Segundo os autores é importante que se oportunize à criança experienciar o contato com diferentes papéis sociais de gênero, dessa forma, é possível uma construção de identidade que abarque a diversidade e o respeito pelas diferenças.

Um número expressivo de profissionais possui ensino superior $(60 \%)$ com graduações que, na maior parte possui algum tipo de relação com a função exercida, com exceção de uma educadora que possui graduação no curso de administração. Apesar desse dado ser positivo, é importante atuar de acordo com o que prezam os documentos oficiais que, por conta de se tratar de um trabalho com uma especificidade da alta complexidade, recomenda como critérios para a seleção desses profissionais a experiência para lidar com crianças, "capacidade de lidar com frustração e separação; habilidade para trabalhar em grupo; disponibilidade afetiva; empatia; capacidade de lidar com conflitos; criatividade; flexibilidade; tolerância; proatividade [sic]; capacidade de escuta; estabilidade emocional" (Relatório da Infância e Juventude 2013, p. 67)

A capacitação surge enquanto uma possibilidade de se reverter possíveis déficits em alguns dos critérios mencionados, além de ela atuar como forma de os profissionais se apropriarem das especificidades que permeiam a instituição de acolhimento (Relatório da Infância e Juventude, 2013). Por meio dela é possível desconstruir o conceito idealizado e romantizado da infância e por meio disso oportunizar aos profissionais um modo pelo qual eles consigam lidar com as particularidades dos comportamentos apresentados pelas crianças que vivenciam a realidade do acolhimento institucional (Trivellato, Carvalho \& Vectore, 2013).

Um dado positivo encontrado diz respeito ao fato de a maioria dos funcionários possuírem capacitação recente $(72 \%)$, no período de dois anos até o momento da coleta. Outro dado benéfico refere-se ao quantitativo de funcionários concursados $(72 \%)$, pois se tratando de uma instituição de acolhimento é importante que se evite a rotatividade de funcionários, porque isso ocasiona em repetidas quebras dos vínculos estabelecidos entre a criança e o funcionário. Sendo assim, a situação de concursado é aquela que acarreta em uma maior segurança tanto para o funcionário quanto para a criança, o que resulta em uma menor possibilidade de uma nova quebra de vínculo para o acolhido (Acioli, Barreira, Lima, Lima \& Assis, 2018; Mendes e Kappler, 2018).

A entrevista realizada com os profissionais foi composta por uma pergunta norteadora: Como você recebe uma criança nova na instituição? Os dados coletados foram analisados pelo software IRaMuTeQ por meio da 
nuvem de palavras, da análise de similitude e da classificação hierárquica descendente (CHD). Referente ao CHD existem duas categorias: categoria 1 - educadores, categoria 2 - equipe técnica. O corpus textual compreende 21 unidades de texto iniciais (UCE's), 92 segmentos de texto, 669 formas distintas e 3199 ocorrências de palavras no texto. Desta análise obteve-se a Nuvem de palavras representativa de como uma criança é recebida na sua chegada à instituição.

Figura 1. Nuvem de palavras representativa de como uma criança é recebida na sua chegada à instituição (Produção do próprio autor).

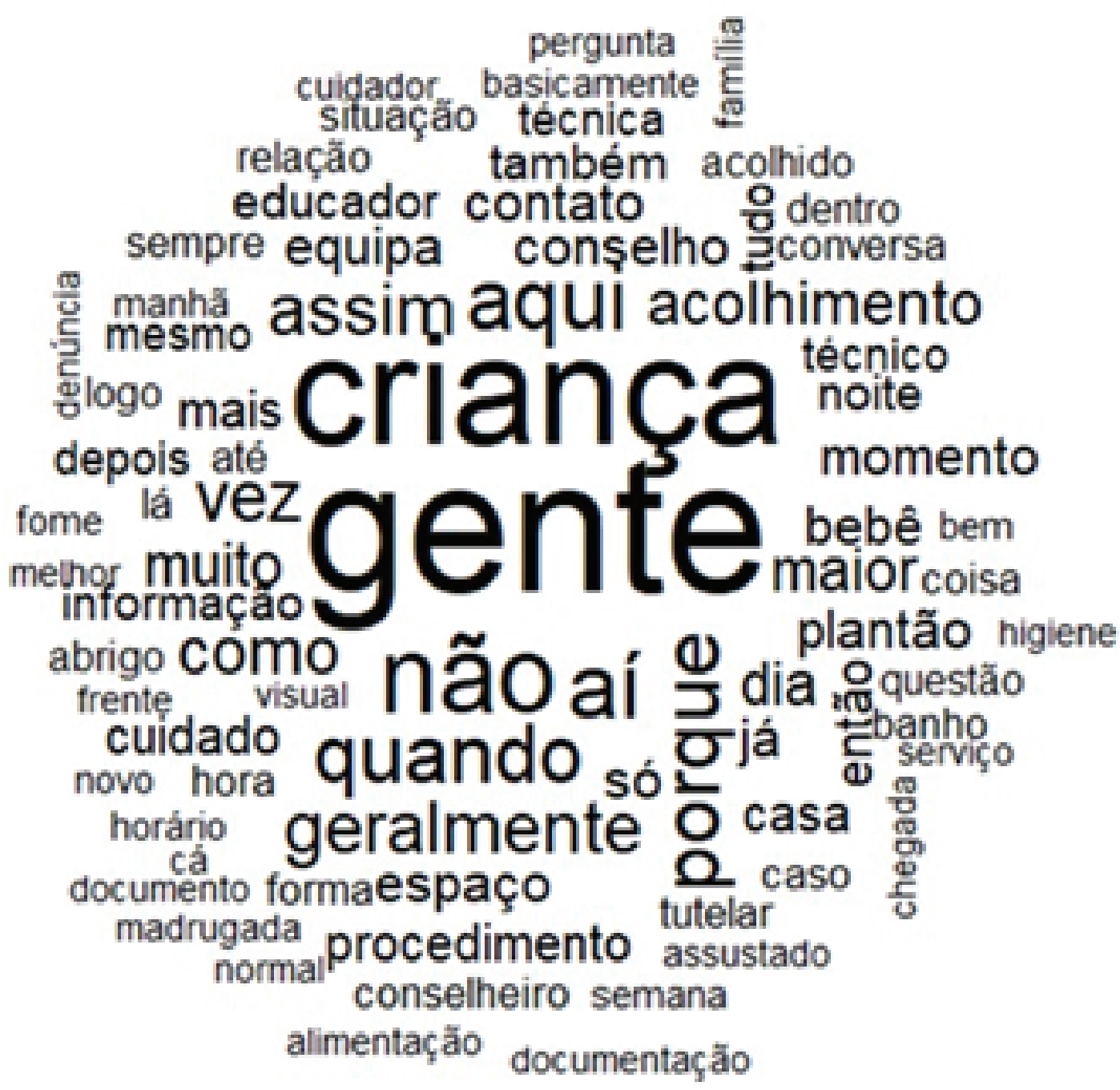

A nuvem de palavras traz como mais relevante o termo "gente", que faz referência à própria equipe e a palavra "criança". Ainda em destaque é possível verificar a palavra "porque", que está relacionada à ação dos profissionais de conversar com as crianças a respeito do motivo de irem para a instituição. Outros termos aparecem de forma menos significativa, como: "conversa" e "informação", essas são ações essenciais no momento da chegada de uma criança nova na instituição, uma vez que proporcionar a ela dados sobre a sua situação é fundamental para uma melhor compreensão e adaptação ao novo contexto.

Um termo que também deveria ser mais presente nas verbalizações dos profissionais é "família", sendo possível perceber que, nos poucos momentos em que o termo foi utilizado indicou a ausência do contato dos educadores com essa família. Tal verbalização aparece enquanto um sinalizador de que possivelmente a rotina da instituição não favorece e/ou promove esse contato. É importante compreender que no momento da chegada 
da criança à instituição, para além de assegurar a garantia das necessidades básicas desse indivíduo é fundamental também que se busque informações a respeito da família dessa criança para a compreensão do caso e estabelecimento de contato.

Outrossim, o fracasso nos processos de reintegração familiar está associado, dentre outros motivos, à fragilidade dos vínculos afetivos da criança com os seus familiares e à ausência de um plano de reintegração que contemple a preparação da família e dos acolhidos para o desligamento. Tais pontos podem ser trabalhados através de ações da equipe que atua na instituição de promover os vínculos familiares. Para isso é importante a interação dos profissionais da instituição de acolhimento com a família do acolhido, pois dessa forma é possível que a rede atue no sentido de promover o resgate das competências familiares (Penso \& Moraes, 2016).

Destes dados foi construída a análise de similitude representativa de como uma criança é recebida na sua chegada à instituição.

Figura 2. Análise de similitude representativa de como uma criança é recebida na sua chegada à instituição (Produção do próprio autor).

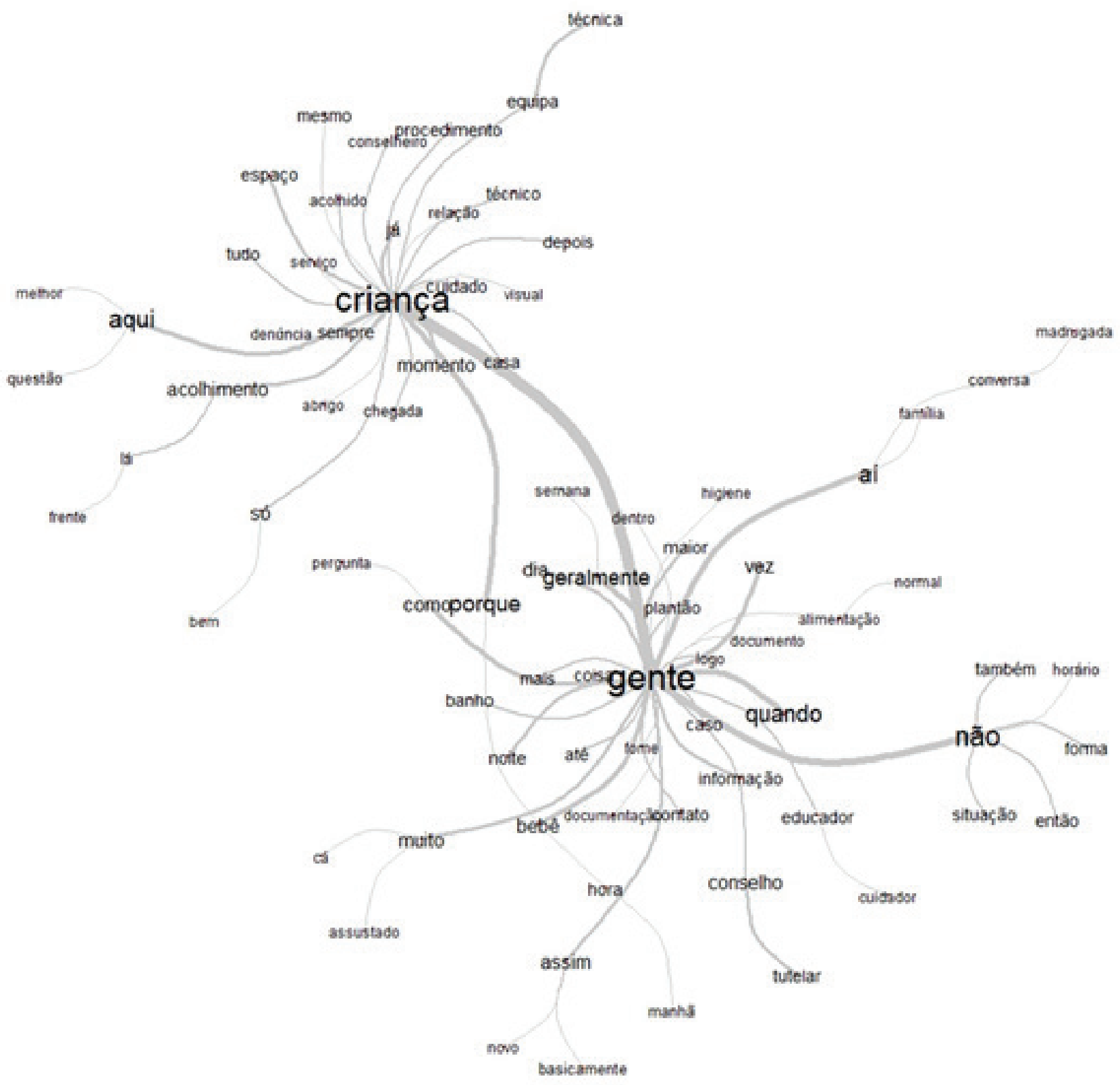


O gráfico de similitude descreve as verbalizações dos profissionais da instituição que demonstram um foco no termo "gente", o qual diz respeito à forma como os profissionais se representam enquanto equipe, esse termo está diretamente ligado à "criança", em uma extremidade e ao "não" na extremidade oposta. O termo central "gente" é muito associado aos procedimentos de rotina, como pode ser verificado nas ramificações "alimento", "documentos", "banho", "conselho tutelar". Além disso, o "cuidado" também aparece associado à "criança", ligado tanto ao cuidado de rotina, mas também ao cuidado referente às questões emocionais da criança.

A palavra criança é associada a palavras como casa, que é uma denominação normalmente utilizada pelos profissionais para indicar a instituição de acolhimento. Apesar de existir no espaço essa percepção da instituição enquanto casa, o estudo de Lauz e Borges (2013) sugere que quando as crianças são solicitadas a representar a vivência de uma casa elas reproduzem vivências anteriores ao acolhimento, ou seja, o que ocorria quando elas viviam com os seus familiares.

$$
\text { O "não" é associado à "situação", "horário", que }
$$
normalmente refere-se às verbalizações nas quais os profissionais mencionavam o fato de as crianças possuírem dificuldade em compreender a situação que se encontravam, tanto em relação ao novo local, quanto em relação à rotina da instituição. As pesquisadoras Cavalcante e Corrêa (2012) elencaram os momentos de maior desgaste emocional para as crianças acolhidas, dentre eles está o período de adaptação ao novo meio ao qual ela foi inserida. Nesse processo a criança necessita se adaptar a hábitos, horários e regras pré-estabelecidos, que até então não faziam parte da sua realidade. Em uma situação como essa a criança irá demandar uma maior atenção, paciência e sensibilidade por parte da equipe da instituição, uma vez que decorrente de todo o estresse advindo desse processo a criança poderá emitir diversos comportamentos inadequados, além de requerer um maior amparo emocional.

Figura 3. Dendograma representativo de como uma criança é recebida na sua chegada à instituição (Produção do próprio autor).

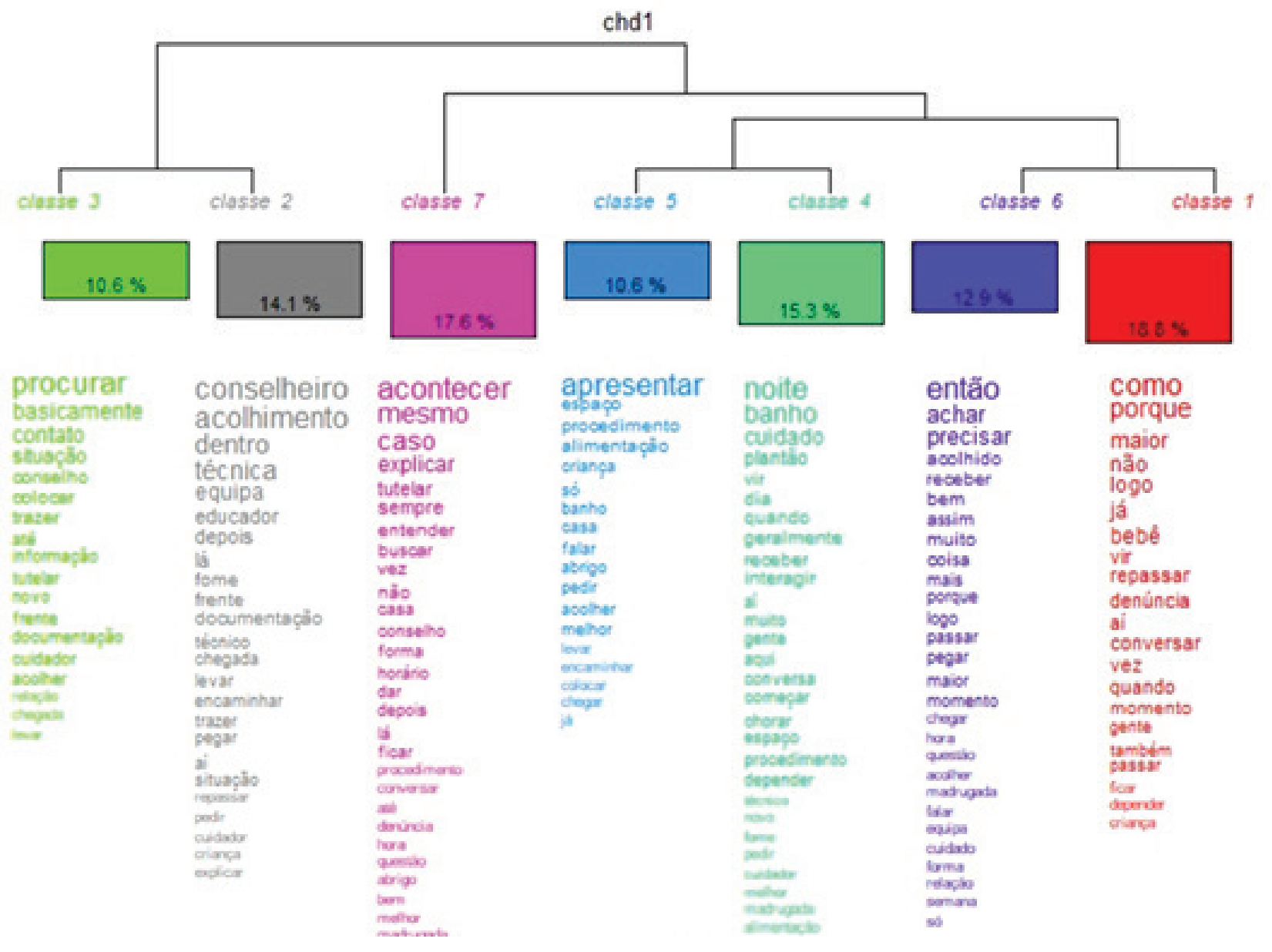




\section{Classe 1 - Diferença no trato entre bebês e crianças}

Corresponde a 18,8\% do corpus, os vocábulos mais frequentes e significativos destes segmentos de textos são: "logo", "maior", "bebê" e "não". Ela está diretamente associada a classe 6 . Os termos encontrados fazem referência à compreensão dos profissionais de que existe diferença no trato dos bebês em relação às crianças maiores no momento da chegada na instituição, no entanto eles não especificam quais são essas diferenças.

\section{Classe 2 - Procedimentos técnicos}

Corresponde a $14,1 \%$ do corpus, os vocabulários mais significativos destes segmentos de textos são: "acolhimento", "conselheiro", "técnica" e "dentro". Ela está diretamente ligada a classe 3 . Os termos encontrados fazem referência aos procedimentos técnicos do momento da chegada de uma criança na instituição, demonstram que o membro da equipe técnica, normalmente o serviço social é o responsável por encaminhar a criança para o interior da instituição e realizar as medidas cabíveis com o conselheiro responsável por trazer o infante.

\section{Classe 3 - Conhecer a situação da criança}

Corresponde a 10,6\% do corpus, os vocábulos mais frequentes e significativos destes segmentos de textos são: "procurar", "contato" e "situação". Ela está associada à categoria 2 que corresponde aos membros da equipe técnica. Os termos encontrados fazem referência à busca realizada, principalmente pela equipe técnica, no sentido de se conhecer mais sobre as informações que o conselheiro traz a respeito da situação da criança, assim como os contatos de familiares.

Como é afirmado por Medeiros e Martins (2018), é responsabilidade da equipe técnica realizar estudo diagnóstico para identificar a necessidade de manter ou não o afastamento da criança do meio familiar e tomar todas as medidas cabíveis em vista de priorizar o melhor à criança. Por consequente, no momento da chegada de uma criança nova à instituição os profissionais devem se apropriar das informações trazidas pelo profissional que a levou até a instituição para a partir disso formular quais medidas a serem tomadas.

\section{Classe 4 - Cuidados básicos}

Corresponde a 15,3\% do corpus, os vocabulários mais frequentes e significativos destes segmentos de textos são: "noite", "banho", "plantão" e "cuidado". Ela está diretamente ligada à classe 5. Para mais, essa classe aparece mais associada à categoria 1, que corresponde aos educadores. Os termos encontrados fazem referência aos cuidados básicos da criança no momento da chegada, como o banho, alimentação, avaliação física. Demonstra também o diferencial existente em relação ao plantão da manhã e da noite, pois quando uma criança chega durante a noite ela é recebida unicamente por educadores.

Os educadores são profissionais que, usualmente, são concebidos enquanto os responsáveis pelos cuidados básicos da criança. No entanto, é importante salientar que a atenção desse profissional deve ir além da garantia dos atendimentos à higiene, à alimentação e aos cuidados diários, ela deve estar voltada também ao amparo das necessidades emocionais (Medeiros \& Martins, 2018).

Para além disso é possível verificar a verbalização dos profissionais que apresentam a instituição enquanto um espaço de cuidado. Guedes e Scarcelli (2014), apontam que as legislações definem a instituição de acolhimento enquanto um lugar de cuidado e proteção, desse modo, esses ideais se caracterizam enquanto algo almejado pelos funcionários. Assim a instituição é percebida como um local onde as crianças estão protegidas, ao passo que qualquer violação de seus direitos está alheia à realidade do espaço.

\section{Classe 5 - Apresentação do espaço}

Corresponde a 10,6 \% do corpus, os vocabulários mais frequentes e significativos destes segmentos de textos são: "procedimento", "espaço" e "criança". Os termos encontrados fazem referência aos procedimentos realizados pelos profissionais, como por exemplo apresentar o espaço físico e social para a criança. Essa apresentação do espaço compreende a exposição das regras existentes no interior da instituição, Almeida (2011) nos apresenta uma das características das instituições de acolhimento que é a existência de regras e rotinas a serem seguidas pelas crianças que na prática elas são concebidas enquanto formas de sujeitar o sujeito. Por isso, uma das formas de se garantir a essa criança o contato com a sua realidade e consequentemente a construção da sua identidade é a partir da afirmação da sua história de vida.

\section{Classe 6 - Acolhida afetuosa}

Corresponde a 12,9\% do corpus, os vocabulários mais frequentes e significativos destes segmentos de textos são: "precisar", "receber" e "acolhido". Os termos encontrados fazem referência a receber a criança através de uma acolhida afetuosa, sendo considerando algo es- 
sencial, pois a criança precisa dessa recepção devido à situação na qual ela foi encaminhada até a instituição. Apesar disso é possível perceber que a representatividade dessa categoria $(12,9 \%)$ é reduzida. Ademais, tem-se na literatura que o apoio afetivo por parte dos profissionais diante da realidade vivenciada pela criança no contexto do acolhimento institucional é capaz de promover resiliência, sentimento de pertencimento, de esperança e de proteção (Bersh, Yunes, Garcia \& Piske, 2018).

\section{Classe 7 - Explicação do processo de acolhimento}

Corresponde a 17,6\% do corpus, os vocabulários mais frequentes e significativos destes segmentos de textos são: "acontecer", "explicar" e "caso". Ela está diretamente ligada às classes 1 e 6 . Os termos encontrados fazem referência aos profissionais que procuram explicar à criança o que a levou até a instituição e o que irá acontecer com ela na instituição e após a sua saída.

Os dados encontrados indicam pontos positivos presentes no discurso dos profissionais, como a preocupação da equipe técnica, nesse momento de procurar o máximo de informações possíveis com os responsáveis por levar a criança ao espaço. Outro dado favorável é que os profissionais se preocupam em atender as necessidades básicas das crianças, mas também os aspectos emocionais, utilizando como um meio para isso a apresentação do espaço. Entretanto, ainda assim, os profissionais percebem que as crianças apresentam dificuldade para se adaptar à rotina da instituição. Um ponto negativo refere-se ao escasso contato existente entre os familiares das crianças e os educadores.

As informações obtidas demonstram a relevância de pesquisar nesta área do conhecimento. Ressalta a importância de ouvir as demandas das crianças, que são os protagonistas dessas instituições e são afetadas por todas as decisões e processos que envolvem o acolhimento.

O estudo traz diversas ramificações passíveis de estudo e aprofundamento, tais como: as interferências no trato com a criança decorrentes da formação do educador; formas de promover o contato dos educadores com os familiares das crianças; percepção das crianças quanto ao momento inicial de chegada na instituição; influências das regras institucionais no desenvolvimento da criança acolhida. Diante disso, é possível tanto a replicação da pesquisa em outras instituições de acolhimento, quanto o aprofundamento de reflexões que surgem a partir das informações e demandas obtidas.

\section{Referências Bibliográficas}

Acioli, R. M. L., Barreira, A. K., Lima, M. L. C. de, Lima, M. L. L. T. de, \& Assis, S. G. de. (2018). Avaliação dos serviços de acolhimento institucional de crianças e adolescentes no Recife. Ciência \& Saúde Coletiva, 23(2), 529-542. https://dx.doi.org/10.1590/1413-81232018232.01172016

Almeida, T. L. (2011). Hupomnêmata: registro de histórias de vida de adolescentes em acolbimento institucional como escrita de si. Dissertação (Mestrado), Programa de Pós-Graduação em Educação, Universidade Estadual de Campinas, Campinas.

Bersh, A. A. S., Yunes, M. A. M., Garcia, N. M. Piske, E. L. (2018). Educador social promotor de boas práticas e resiliência em instituições de acolhimento. In Cavalcante, L. I. C.; Magalhães, C. M. C.; Corrêa, L.S.; Costa, E. F. \& Cruz, D. A. (Org.). Acolbimento institucional de crianças e adolescentes (pp. 253-266). Curitiba: Juruá.

Bowlby, J. (1979/2001). Formação e rompimento dos laços afetivos. São Paulo: Martins Fontes.

Orientações Técnicas para acolhimento de crianças e adolescentes (2009). Brasil, Conselho Nacional dos Direitos da Criança e do Adolescente e Conselho Nacional de Assistência Social. Conanda.

Relatório da infância e juventude. Brasil(2013). Um olhar mais atento aos serviços de acolhimento de crianças e adolescentes no país. Relatório da resolução no 71/2011. Brasília: Conselho Nacional do Ministério Público.

Bueno, R. K.; Magalhães, C. M. C. \& Vieira, M. L. (2018). A importância da figura masculina do cuidador/educador em instituições de acolhimento. In Cavalcante, L. I. C.; Magalhães, C. M. C.; Corrêa, L. S.; Costa, E. F. \& Cruz, D.A. (Org.). Acolbimento institucional de crianças e adolescentes (pp. 115 124). Curitiba: Juruá.

Cavalcante, L. I. C. (2008). Ecologia do Cuidado: Interações entre a criança, o ambiente, os adultos e seus pares em instituição de Abrigo. Tese(Doutorado). Programa de Pós-Graduação em Teoria e Pesquisa do Comportamento, Universidade Federal do Pará, Belém.

Cavalcante, L. I. C., \& Corrêa, L. S. (2012). Perfil e trajetória de educadores em instituição de acolhimento infantil. Cadernos de Pesquisa, 42(146), 494-517. https://dx.doi.org/10.1590/S0100-15742012000200010

Cavalcante, L. I. C., Silva, S. S. C., \& Magalhães, C. M. C. (2010). Institucionalização e reinserção familiar de crianças e adolescentes. Revista Mal Estar e Subjetividade, 10(4), 1147-1172. Recuperado em 03 de outubro de 2018, de http://pepsic.bvsalud.org/scielo.php?script=sci_arttext\&pid=S1518$-61482010000400005 \& \operatorname{lng}=\mathrm{pt} \& \ln g=\mathrm{pt}$

Cintra, A. L., \& Souza, M. de. (2010). Institucionalização de crianças: leituras sobre a produção da exclusão infantil, da instituição de acolhimento e da prática de atendimento. Revista Mal Estar e Subjetividade, 10(3), 809-833. Recuperado em 15 de agosto de 2018, de http://pepsic.bvsalud.org/scielo. php?script $=$ sci_arttext\&pid $=$ S1518-61482010000300006\&lng $=$ pt\&tlng $=$ pt

Corrêa, L. S. (2016). Serviços de acolhimento institucional de crianças e adolescentes na região metropolitana de Belém: os ambientes, os acolbidos e os Educadores. Tese (Doutorado) - Programa de Pós-Graduação em Teoria e Pesquisa do Comportamento, Universidade Federal do Pará, Belém.

Cruz, D. A. (2014). Conta que eu conto: Percepções de Crianças sobre suas Experiências de Acolbimento. 2014. 128 f. Dissertação (Mestrado) - Programa de Pós-Graduação em Teoria e Pesquisa do Comportamento, Universidade Federal do Pará, Belém.

Guedes, C. F., \& Scarcelli, I. R. (2014). Acolhimento institucional na assistência à infância: o cotidiano em questão. Psicologia e Sociedade, 26(spe), 58-67. https://dx.doi.org/10.1590/S0102-71822014000500007

Lauz, G. V. M., \& Borges, J. L. (2013). Concepção de família por parte de crianças em situação de acolhimento institucional e por parte de profissionais. Psicologia: Ciência e Profissão, 33(4), 852-867. https://dx.doi.org/10.1590/ S1414-98932013000400007

ECA (1990) Lei 13.509, de 22 de novembro de 2017. (2017, 22 de novembro). Dispõe sobre adoção e altera a Lei no 8.069, de 13 de julho de 1990 (Estatuto da Criança e do Adolescente), a Consolidação das Leis do Trabalho (CLT), aprovada pelo Decreto-Lei no 5.452, de 1 o de maio de 1943, e a Lei no 10.406, de 10 de janeiro de 2002 (Código Civil). Brasília, DF: Casa Civil, Subchefia para assuntos jurídicos. Recuperado em 20 de outubro, 2018, de http://www.planalto.gov.br/ccivil_03/_Ato2015-2018/2017/ Lei/L13509.htm\#art1 
ECA (1990) - Lei n 8.069, de 13 de julho de 1990. (1990, 13 de julho). Dispõe o Estatuto da Criança e do Adolescente e dá outras providências. Brasília, DF: Casa Civil, Subchefia para assuntos jurídicos. Recuperado em 03 outubro, 2018, de http://www.planalto.gov.br/ccivil_03/Leis/L8069.htm

Medeiros, B. C. D. de, \& Martins, J. B. (2018). O Estabelecimento de Vínculos entre Cuidadores e Crianças no Contexto das Instituições de Acolhimento: um Estudo Teórico. Psicologia: Ciência e Profissão, 38(1), 74-87. https://dx.doi. org/10.1590/1982-3703002882017

Mendes, D. M. L. \& Kappler, S. R. (2018). Afetividade e socialização da emoção no contexto de acolhimento institucional: os educadores sociais como agentes no desenvolvimento emocional infantil. In Cavalcante, L. I. C.; Magalhães, C. M. C.; Corrêa, L. S.; Costa, E. F. \& Cruz, D. A. (Org.). Acolbimento institucional de crianças e adolescentes (pp. 221-236). Curitiba: Juruá.

Penso, M. A. \& Moraes, P. J. F. de S. (2016). Reintegração familiar e múltiplos acolhimentos institucionais. Revista Latinoamericana de Ciencias Sociales, Niñes y Juventud, 14 (2), pp. 1523-1535. http://www.scielo.org.co/pdf/rlcs/v14n2/ v14n2a44.pdf

Rosa, E. M., Nascimento C. R. R., Santos A. P., Melo C. R. S. \& Souza M. R. (2016). Inserção ecológica em uma instituição de acolhimento para crianças no Espírito Santo. In Koller, S. H., Morais, N. A. \& Paludo, S. S. (Org.). Inserção Ecológica: Um método de estudo em desenvolvimento bumano (pp. 95-118). São Paulo: Casa do Psicólogo.
Rossetti-Ferreira, M. C., Almeida, I. G. de, Costa, N. R. do A., Guimarães, L. de A., Mariano, F. N., Teixeira, S. C. de P. (2012). Acolhimento de crianças e adolescentes em situações de abandono, violência e rupturas. Psicologia: Reflexão e Crítica, 25(2), 390-399. https://dx.doi.org/10.1590/ S0102-79722012000200021

Trivellato, A. J., Carvalho, C., \& Vectore, C. (2013). Escuta afetiva: possibilidades de uso em contextos de acolhimento infantil. Psicologia Escolar e Educacional, 17(2), 299-307. https://dx.doi.org/10.1590/S1413-85572013000200012

Agradecimentos ao CNPq pelo apoio e financiamento - Proc. N 302256/2017-2.

Submetido em: 8-2-2019

Aceito em: 18-7-2019 